\title{
Ramadan Fasting and its Influence on Serum Osmolality in Emergency Patients
}

\begin{abstract}
Keywords: Serum osmolality; Fasting; Ramadan; Emergency department

Abstract

Introduction: Ramadan is the ninth month of the Islamic calenda and Muslims fasting during this month. The effect of Ramadan fasting has been studied in various studies which are conducted on normal healthy individuals worldwide, but the changes of serum osmolality during Ramadan fasting are not known well. We aimed to investigate clinical worthiness of serum osmolality on fasting patients at Emergency Department (ED).
\end{abstract}

Methods: This prospective, cross-sectional, case-control study was conducted on 62 fasting patients and 62 age- and sex- matched non-fasting controls in a tertiary training and research hospital ED. We obtained demographic, clinical and laboratory data including serum sodium, glucose, blood urea nitrogen, systolic and diastolic blood pressure, pulse rate and ED outcomes including discharge and hospitalization status in study and control patients. All analyses were performed using SPSS version 15.0 for Windows.

Results: A total of 124 patients enrolled into the study. The median serum osmolality averages of the study and control group were found as $300 \mathrm{mosm} / \mathrm{kg}$ (IQR = 295-304) and $299 \mathrm{mosm} / \mathrm{kg}$ (IQR = 296-305), respectively ( $\mathrm{p}=0.990)$. In the study group, statistically significant positive correlation was observed between serum osmolality and duration of hunger, age, urea, creatinine, sodium levels $(p=0.007, p<$ $0.001, p<0.001, p=0.002, p<0.001)$

Conclusion: This study has shown that serum osmolality isn't affected by Ramadan fasting on ED patients. Nonetheless, further prospective larger studies are needed to assess the relationship between serum osmolality and Ramadan fasting.

\section{Introduction}

Ramadan is the ninth month of the Islamic calendar. It is the holiest month and all healthy adult Muslims fast during this month. Each day during this month, Muslims are commanded to abstain from food and drink from sunrise to sunset. Food and fluid intake is mainly nocturnal and daily sleep duration and physical activity is usually reduced. The studies about the Ramadan were usually mentioned on healthy volunteers and blood samples were collected before and after the Ramadan. These studies were evaluated usually weight loss, reduction in BMI, lipid profile changes, hormonal changes and biochemical changes and researches indicate that fasting in Ramadan can cause changes in body components, serum electrolyte intensity, and serum osmolality [1-10]. However, the changes of serum osmolality during Ramadan fasting are not known well.

The serum osmolality is a measure of the different solutes in plasma and it is expressed as miliosmols per kilogram (mosm/ $\mathrm{kg}$ ). It is primarily determined by serum electrolytes (sodium, chloride, bicarbonate), glucose and urea. The reference range of serum osmolality is $275-290 \mathrm{mosm} / \mathrm{kg}$. Various conditions are associated with increased (hyperglycemia, diabetic ketoacidosis,

\section{Journal of}

Emergency Medicine \& Critical Care

\author{
Ozlem Dikme $^{1 *}$ and Ozgur Dikme ${ }^{2}$ \\ ${ }^{I}$ Department of Emergency Medicine, Koc University Medical \\ Faculty Hospital, Istanbul, Turkey \\ ${ }^{2}$ Department of Emergency Medicine, Istanbul Training and \\ Research Hospital, Istanbul, Turkey

\section{Address for Correspondence} \\ Ozlem Dikme, MD, Emergency Physician, Department of \\ Emergency Medicine, Koc University Medical Faculty Hospital, \\ Davutpaşa Mah. No:4, Topkapi, Istanbul 34010, Turkey, Tel: \\ +905056487292; E-mail: ozlemakinci80@yahoo.com \\ Submission: 09 June, 2016 \\ Accepted: 21 July, 2016 \\ Published: 26 July, 2016 \\ Copyright: $\odot 2016$ Dikme O. This is an open access article distributed \\ under the Creative Commons Attribution License, which permits \\ unrestricted use, distribution, and reproduction in any medium, provided \\ the original work is properly cited.
}

nonketotic hyperosmolar hyperglysemic coma, diabetes insipidus, hypernatremia, alcohol ingestion) and decreased (hyponatremia, syndrome of inappropriate antidiuretic hormone, adrenal insufficiency, cirrhosis, congestive heart failure, nephrotic syndrome) serum osmolality.

The aim of this study was to compare serum osmolality between fasting ED patients and a non-fasting control group during Ramadan, to analyze the correlations between serum osmolality and demographical and biochemical parameters.

\section{Material and Methods}

This prospective, cross-sectional, case-control study was conducted in Istanbul, Turkey in 2013 when Ramadan fasting occurred between July 8 and August 7 . We enrolled 62 fasting patients and 62 age- and sex- matched non-fasting controls with any complaint admitted to Istanbul Training and Research Hospital ED. This study was approved by the local ethical committee and informed consent was obtained from each patient for the blood draws, and review of medical records, according to a protocol approved by the Institutional Committee on Human Investigation.

The study group included 18 age and older fasting patients who admitted to the ED with any complaint and was planned biochemical tests which were covered glucose, blood urea nitrogen and sodium by an emergency physicians regardless of the study $(n=62)$. The control group included non fasting ED admitted patients with any complaint in the same day and time zone, who had same sex, age range and was planned same biochemical tests $(n=62)$. Exclusion criteria included age under 18, dehydration in clinically, sepsis, burn, poisoning, mannitol use, known renal disease, define hyponatremia or hypernatremia, hyperglycemia, prior diabetes mellitus or diabetes insipidus or syndrome of inappropriate antidiuretic hormone, using $\mathrm{ADH}$ therapy, being unable to fasting on admission, being not planned to biochemical examinations by physicians, respectively. 
Citation: Dikme O, Dikme O. Ramadan Fasting and its Influence on Serum Osmolality in Emergency Patients. J Emerg Med Critical Care. 2016;2(1): 4.

ISSN: $2469-4045$

All subjects were evaluated in the ED triage area and they took appropriate triage category regardless of the study settings. Age, gender, ED admission time, complaint and vital signs were noted. Subjects were examined by an emergency physician and final diagnosis was reported. Also, patient's outcome was noted as discharge or admission to the ward or Intensive Care Unit (ICU). They were used to measured primary goal substantially and compared with osmolality levels between fasting and non fasting patients. Serum osmolality was calculated using a linear equation which is defined as Serum osmolality $=($ serum $\mathrm{Na} \times 2)+($ Glucose in $\mathrm{mg} / \mathrm{dL} / 18)+($ Blood Urea Nitrogen, in $\mathrm{mg} / \mathrm{dL} / 2.8)$. All of the subjects were followed up until discharged from the hospital. Patient information was collected from medical records and by interviews.

Statistical analysis was performed using the Statistical Package for the Social Sciences (SPSS) version 15.0 for Windows statistical software (IBM, Armonk, NY). Descriptive statistics were given as the number and percentage for the categorical variables and the median and inter quartile range (IQR) for the numeric variables. The Kolmogorov-Smirnov tests were used to analyze the normal distribution of the variables. Mann-Whitney $U$ test and KruskalWallis test were used to test for differences between and within groups. Subgroup analyzes performed with Mann-Whitney U test with Bonferroni correction was interpreted. Differences in means were computed with corresponding $95 \%$ confidence intervals (CIs). Rates of categorical variables between groups were tested by Chisquare analysis. Monte Carlo simulation was performed which conditions cannot be provided in case. Quantitative variables are determining factors backward linear regression analysis was determined by the method. Alpha level of statistical significance of $p$ $<0.05$ was considered to be statistically significant.

\section{Results}

One hundred thirty two consecutive patients were assessed for study group eligibility and $70(53 \%)$ patients were excluded (Figure 1). A total of 124 patients (study/control ratio of 62:62) were included into the study. The characteristics of study participants are shown in Table 1. When the subjects evaluated about their diagnosis there

Table 1: Characteristics of subjects.

\begin{tabular}{|c|c|c|c|}
\hline Characteristics & $\begin{array}{l}\text { Study group (n } \\
=62 \text { ) }\end{array}$ & $\begin{array}{l}\text { Control group ( } \mathrm{n} \\
=62 \text { ) }\end{array}$ & $\mathbf{p}$ \\
\hline Age, Median (IQR) & $41.5(26-56)$ & $40.5(26-57)$ & 0.871 \\
\hline Male, $\mathrm{n}(\%)$ & $31(50.0 \%)$ & $31(50.0 \%)$ & 1.000 \\
\hline Night Admissions, $\mathrm{n}(\%)$ & $47(75.8 \%)$ & $47(75.8 \%)$ & 1.000 \\
\hline Fasting days, Median (IQR) & $18(12-24)$ & 0 & $\mathrm{n} / \mathrm{a}$ \\
\hline $\begin{array}{l}\text { Duration of hunger, Median } \\
\text { (IQR) }\end{array}$ & $15(13-16)$ & 0 & $\mathrm{n} / \mathrm{a}$ \\
\hline $\begin{array}{l}\text { Systolic BP }(\mathrm{mmHg}) \text {, Median } \\
\text { (IQR) }\end{array}$ & $128(115-136)$ & $124.5(115-130)$ & 0.548 \\
\hline $\begin{array}{l}\text { Diastolic BP }(\mathrm{mmHg}) \text {, Median } \\
(\mathrm{IQR})\end{array}$ & $70(68-80)$ & $70(70-80)$ & 0.836 \\
\hline $\begin{array}{l}\text { Heart rate(beat/min), Median } \\
(I Q R)\end{array}$ & $82(76-86)$ & $82.5(75-90)$ & 0.464 \\
\hline
\end{tabular}

Categorical values expressed as the number and percentage and numeric variables expressed as the median and IQR. Mann Whitney $U$ and chi-square tests were obtained.

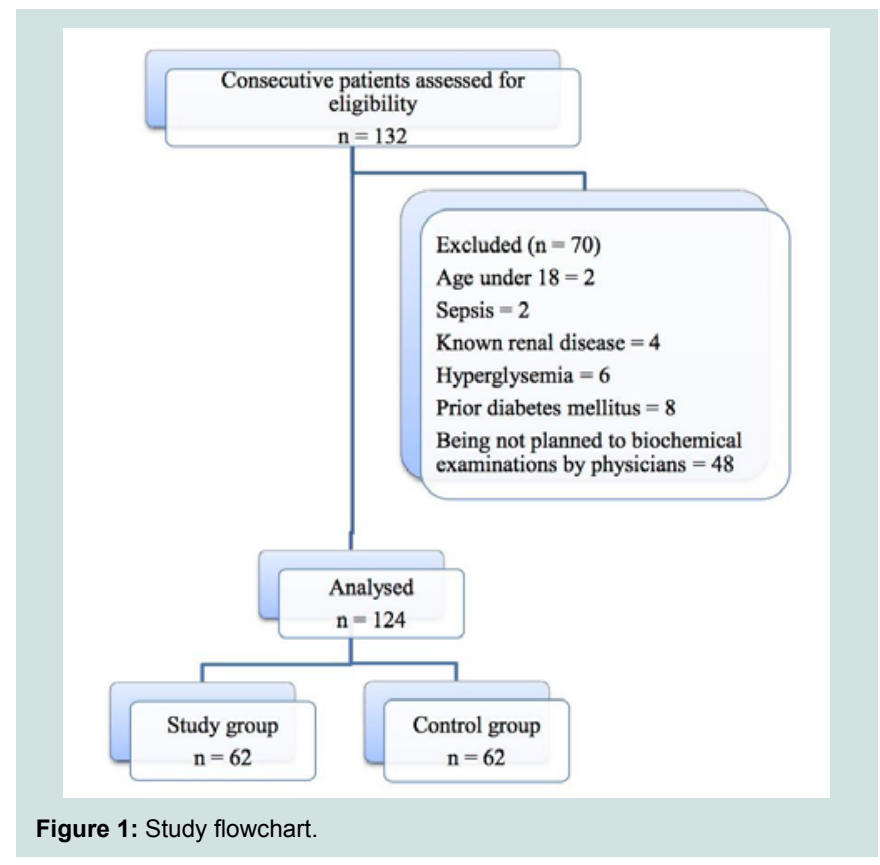

Table 2: Biochemical parameters of the study and control groups.

\begin{tabular}{|l|l|l|l|}
\hline & Study Group & Control Group & p \\
\hline Osmolality (mosm/kg) & $300(295-304)$ & $299(296-305)$ & 0.990 \\
\hline Glucose (mg/dL) & $98.5(89-112)$ & $107(94-125)$ & 0.144 \\
\hline Urea (mg/dL) & $31(26-39)$ & $30(28-45)$ & 0.397 \\
\hline Creatinin (mg/dL) & $0.9(0.8-1.0)$ & $0.9(0.8-1.1)$ & 0.731 \\
\hline Sodium (mmol/L) & $141(139-143)$ & $140.5(139-142)$ & 0.320 \\
\hline Potassium (mmol/L) & $4.3(4.0-4.5)$ & $4.0(3.9-4.4)$ & 0.352 \\
\hline
\end{tabular}

All values expressed as Median and IQR. Mann Whitney $U$ Tests used.

was statistically significant difference between the study and control group ( $\mathrm{p}<0.001)$. The most common diagnosis was related with neurological and gastrointestinal systems in the study group and was related with gastrointestinal and cardiovascular systems in the control group. In the study group, 52 (83.9\%) patients were discharged, $10(16.1 \%)$ patients were hospitalized and $3(4.8 \%)$ of them were admitted to the ICU. In the control group, 58 (93.5\%) patients were discharged, 4 (6.5\%) patients were hospitalized and 1 (1.6\%) of them were admitted to ICU. There was no statistically significant difference between two groups outcomes ( $\mathrm{p}=0.255)$.

Serum osmolality averages of the study and control group were $300 \mathrm{mosm} / \mathrm{kg}(\mathrm{IQR}=295-304)$ and $299 \mathrm{mosm} / \mathrm{kg}(\mathrm{IQR}=$ 296-305), respectively $(p=0.990)$. Biochemical parameters of the study and control groups are shown in Table 2. In the study group, serum osmolality was compared with duration of hunger, age, urea, creatinine, sodium levels respectively, there was observed statistically significant positive correlation (respectively, $\mathrm{p}=0.007, \mathrm{p}$ $<0.001, \mathrm{p}<0.001, \mathrm{p}=0.002, \mathrm{p}<0.001$ ) (Table 3). When the other biochemical results evaluated in terms of fasting days, glucose had a negative correlation $(\mathrm{p}=0.001)$, sodium and potassium had a positive correlation $(\mathrm{p}=0.010, \mathrm{p}=0.007)$. Also sodium had a positive correlation with duration of hunger $(\mathrm{p}=0.024)$. Glucose 
Citation: Dikme O, Dikme O. Ramadan Fasting and its Influence on Serum Osmolality in Emergency Patients. J Emerg Med Critical Care. 2016;2(1): 4.

ISSN: $2469-4045$

Table 3: Relationship between osmolality and characteristics and other biochemical parameters of subjects in the study group.

\begin{tabular}{|l|l|l|}
\hline & Osmolality & p \\
\hline Fasting days & 0.137 & 0.290 \\
\hline Duration of hunger & 0.337 & $\underline{\mathbf{0 . 0 0 7}}$ \\
\hline Systolic BP & 0.191 & 0.137 \\
\hline Diastolic BP & -0.072 & 0.576 \\
\hline Heart rate & 0.006 & 0.966 \\
\hline Age & 0.430 & $\leq \mathbf{0 . 0 0 1}$ \\
\hline Glucose & 0.117 & 0.364 \\
\hline Urea & 0.724 & $\leq \mathbf{0 . 0 0 1}$ \\
\hline Creatinin & 0.385 & $\underline{\mathbf{0 . 0 0 2}}$ \\
\hline Sodium & 0.566 & $\leq \mathbf{0 . 0 0 1}$ \\
\hline Potassium & -0.080 & 0.536 \\
\hline
\end{tabular}

and urea had a positive correlation with age $(\mathrm{p}<0.001, \mathrm{p}<0.001)$ (Table 4). However, when the osmolality was evaluated in terms of hospitalization status, there was not any statistical difference between hospitalized and discharged patients $(\mathrm{p}=0.410$ in study group, $\mathrm{p}=$ 0.749 in totally).

\section{Discussion}

Ramadan occurs at different times in the year over a 33-year cycle. The period in the person fasts may vary depending on the geographical location of the country and the seasons of the year. It can be as long as 18 hours in the summer. In 2013 Ramadan was in the July and the fasting time was approximately 16 hours in Istanbul, Turkey. In this study, statistically significant positive correlation was observed between fasting patients' serum osmolality and duration of hunger. Serum osmolality increase might be due to dehydration and not consuming enough liquids during the day. However, in our study when we evaluated the non-fasting patients, their serum osmolality was also found increased than expected and there was no statistically or clinically difference between fasting and non-fasting patients. It can be explained with being in summer season and predisposition to dehydration.

The elderly patient has a diminished reserve of water balance and an impaired regulatory mechanism. Thirst sensation, concentrating abilities and hormonal modulators of salt and water balance are sluggish and highly susceptible to being overtaken by morbid or iatrogenic events. Therefore, elder have higher osmolality levels than younger. In similar to the literature, we found a positive correlation between age and serum osmolality levels. In the literature there are some already known studies about osmolality and ageing relation. In 1992, McLean et al. reported age associated increase in plasma osmolality in 152 randomly selected subjects and in the same year same authors published a review about water homeostasis and ageing $[11,12]$. In 2014 Hooper et al. wrote a review on same issue and they pointed that the serum osmolality is the most appropriate gold standard for diagnosis of water-loss dehydration [13].

Studies report that the effect of the Ramadan fasting on osmolality levels has been conflicting and inconsistent. In our study, we found that the serum osmolality of fasting ED patients did not affect the hospitalization rate. Also, when we compared with the fasting and non-fasting patients there was no significant difference in terms of serum osmolality. Similarly with our study, literature says that there isn't a consensus on osmolality changes during fasting. Ziaee et al. says that the Ramadan fasting leads to increased serum osmolality in both genders, but these changes remain within normal range [14]. Also Hosseini et al. says that regular exercise in case of fasting in Ramadan led to some changes in serum osmolality, electrolytes and water [15]. Additionally, in some studies urinary osmolality was used a parameter of dehydration. Cheah et al. found that Ramadan fasting did not affect the urine osmolality [6]. In contrast Shirreffs et al. reported that obligatory urine output decreased and urinary concentration increased [7]. Similarly Mustafa et al. found that daytime urine osmolality tended to increase [8].

Many previous studies which have been published about the effect of fasting on renal function tests reported small changes that were not statistically significant $[1-3,16]$. In our study, renal function tests were considered, there was no statistically significant difference, too. When increased the number of the fasting days, we found that the sodium and potassium levels were increased but glucose level was decreased. Other studies have also reported marked decline in the glucose level during the Ramadan [1]. This finding strongly indicates the beneficial effects of Islamic fasting in diminishing plasma glucose. The increasing number of fasting days led to an increase in dehydration may have led to changes in serum electrolytes such as sodium and potassium. Tralbelski et al. find that like our study, fasters experienced an increase in the serum concentrations of urea, creatinine, sodium and potassium from before the Ramadan to end of the Ramadan [9]. Unlike our study Hosseini et al. found that potassium levels decreased but creatinine, urea and uric acid levels

Table 4: Biochemical parameters and characteristics of subjects in the study group.

\begin{tabular}{|c|c|c|c|c|c|c|c|c|c|c|}
\hline & \multicolumn{2}{|c|}{ Glucose } & \multicolumn{2}{|c|}{ Urea } & \multicolumn{2}{|c|}{ Creatinin } & \multicolumn{2}{|c|}{ Sodium } & \multicolumn{2}{|c|}{ Potassium } \\
\hline & rho & $p$ & rho & $\mathbf{p}$ & rho & $\mathbf{p}$ & rho & p & rho & $\mathbf{p}$ \\
\hline Day & -0.411 & $\underline{0.001}$ & 0.026 & 0.839 & 0.182 & 0.157 & 0.325 & $\underline{0.010}$ & 0.337 & $\underline{0.007}$ \\
\hline Hour & -0.086 & 0.507 & 0.123 & 0.340 & 0.169 & 0.190 & 0.286 & $\underline{0.024}$ & -0.066 & 0.610 \\
\hline SBP & 0.157 & 0.223 & 0.148 & 0.252 & 0.226 & 0.077 & 0.075 & 0.564 & 0.072 & 0.576 \\
\hline DBP & 0.147 & 0.254 & -0.239 & 0.062 & 0.194 & 0.130 & 0.055 & 0.672 & -0.088 & 0.494 \\
\hline HR & 0.152 & 0.239 & -0.007 & 0.960 & 0.054 & 0.678 & -0.035 & 0.788 & -0.095 & 0.464 \\
\hline Age & 0.477 & $\leq 0.001$ & 0.535 & $\leq 0.001$ & 0.146 & 0.256 & -0.055 & 0.669 & -0.020 & 0.875 \\
\hline
\end{tabular}


Citation: Dikme O, Dikme O. Ramadan Fasting and its Influence on Serum Osmolality in Emergency Patients. J Emerg Med Critical Care. 2016;2(1): 4.

increased. In same study, variance between groups only in variable urea was significant [15].

\section{Conclusion}

According to our study there is no influence of the Ramadan fasting on serum osmolality in the ED. However, when the other biochemical results evaluated in terms of fasting days, glucose had a negative correlation, sodium and potassium had a positive correlation. Due to our results, patients with history of diabetes or prior electrolyte disorders who are also fasting in Ramadan should be observed with carefully in the ED and aware about these biochemical complications. It seems that more researches are required for evaluating the effects of the Ramadan fasting on serum osmolality and there are yet many unanswered questions in this situation.

\section{References}

1. Attarzadeh Hosseini SR, Hejazi K (2013) The effects of ramadan fasting and physical activity on blood hematological-biochemical parameters. Iran J Basic Med Sci 16: 845-849

2. Dewanti L, Watanabe C, Sulistiawati, Ohtsuka R (2006) Unexpected changes in blood pressure and hematological parameters among fasting and nonfasting workers during Ramadan in Indonesia. Eur J Clin Nutr 60: 877881.

3. Unalacak M, Kara IH, Baltaci D, Erdem O, Bucaktepe PG, et al. (2011) Effects of Ramadan fasting on biochemical and hematological parameters and cytokines in healthy and obese individuals. Metab Syndr Relat Disord 9: 157-161.

4. Ziaee V, Razaei M, Ahmadinejad Z, Shaikh H, Yousefi R, et al. (2006) The changes of metabolic profile and weight during Ramadan fasting. Singapore Med J 47: 409-414.
5. Leiper JB, Molla AM, Molla AM (2003) Effects on health of fluid restriction during fasting in Ramadan. Eur J Clin Nutr 57 Suppl 2: S30-S38.

6. Cheah SH, Ch'ng SL, Husain R, Duncan MT (1990) Effects of fasting during Ramadan on urinary excretion in Malaysian Muslims. Br J Nutr 63: 329-337.

7. Shirreffs SM (2003) Markers of hydration status. Eur J Clin Nutr 57 Suppl 2: S6-S9.

8. Mustafa KY, Mahmoud NA, Gumaa KA, Gader AM (1978) The effects of fasting in Ramadan. 2. Fluid and electrolyte balance. Br J Nutr 40: 583-589.

9. Trabelsi K, Stannard SR, Maughan RJ, Jammoussi K, Zeghal K, et al. (2012) Effect of resistance training during Ramadan on body composition and markers of renal function, metabolism, inflammation, and immunity in recreational bodybuilders. Int J Sport Nutr Exerc Metab 22: 267-275.

10. Fakhrzadeh H, Larijani B, Sanjari M, Baradar-Jalili R, Amini MR (2003) Effect of Ramadan fasting on clinical and biochemical parameters in healthy adults. Ann Saudi Med 23: 223-226.

11. McLean KA, O'Neill PA, Davies I, Morris J (1992) Influence of age on plasma osmolality: a community study. Age Ageing 21: 56-60.

12. O'Neill PA, McLean KA (1992) Water homestasis and aging. Med Lab Sci 49: 291-298.

13. Hooper L, Bunn D, Jimoh FO, Fairweather-Tait SJ (2014) Water-loss dehydration and aging. Mech Ageing Dev 136-137: 50-58.

14. Ziaee V, Yousefi R, Ahmadinejad Z, Shaikh H, Rezaei M, et al. (2007) The effect of Ramadan fasting on serum osmolality, some electrolytes and hematological parameters. Iranian Journal of Endocrinology and Metabolism 9: 47-53.

15. Attarzadeh Hosseini SR, Sardar MA, Hejazi K, Farahati S (2013) the effect of ramadan fasting and physical activity on body composition, serum osmolality levels and some parameters of electrolytes in females. Int J Endocrinol Metab 11: 88-94.

16. Miladipour AH, Shakhssalim N, Parvin M, Azadvari M (2012) Effect of Ramadan fasting on urinary risk factors for calculus formation. Iran J Kidney Dis 6: 33-38. 